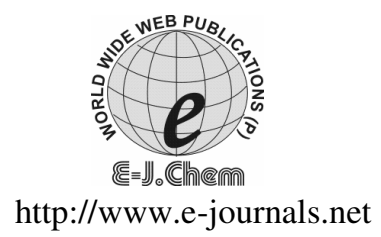

ISSN: 0973-4945; CODEN ECJHAO

E-Journal of Chemistry

Vol. 5, No.4, pp. 774-781, October 2008

\title{
Enhancement of the Inhibitor Efficiency of Atropine Methochloride in Corrosion Control of Mild Steel in Sulphuric Acid
}

\author{
ABIDA BEGUM*, HARIKRISHNA.S ${ }^{\S}$, IRFANULLA KHAN ${ }^{\#}$ and VEENA K \\ *Department of Chemistry, P.E.S School of Engineering, Bangalore, \\ ${ }^{\S}$ Shirdi Sai Engg. College, Bangalore, \\ "Mohammed Ishaque Khan College, Bangalore, \\ Maharanis Science College, Bangalore, India. \\ drabid.drabida@gmail.com
}

Received 28 November 2007; Revised 29 January 2008; Accepted 20 March 2008

\begin{abstract}
The inhibition efficiency and synergistic behaviour of $10^{-4} \mathrm{M}$ Atropine methochloride was carried out using mass loss and polarisation methods in the presence of (i) metal ions, $\mathrm{Ni}^{2+}$ and $\mathrm{Cu}^{2+}$ between $10^{-2} \mathrm{M}$ to $10^{-6} \mathrm{M}$ concentrations, (ii) different concentrations of metal ions and $10^{-3} \mathrm{M} \mathrm{I}^{-}, 10^{-3} \mathrm{M} \mathrm{Cl}^{-}$and $10^{-3} \mathrm{M} \mathrm{Br}^{-}$ solutions and (iii) different metal ions, $10^{-3} \mathrm{M} \mathrm{I}^{-}$and at three different temperatures. The analysis reveals that the inhibition efficiency of Atropine methochloride was maximum at $10^{-2} \mathrm{M}$ in 5 hours of immersion period. Halides decreased the corrosion rate of mild steel in Sulphuric acid. The decrease is maximum with $10^{-3} \mathrm{M} \mathrm{I}^{-}$. As the temperature increased from $298 \mathrm{~K}$ to $308 \mathrm{~K}$, the inhibition efficiency gradually decreased. The inhibitor was found to be effective up to $303 \mathrm{~K}$
\end{abstract}

Keywords: Atropine Methochloride (AMCl); Metal ions; Halides; Temperature resistant.

\section{Introduction}

Mild steel has been extensively used under different conditions in chemical and allied industries in handling alkalis, acids and salt solution. Mild steel undergoes corrosion during acid cleaning, pickling, decaling, mining and oxidizing of oil wells. Corrosion rate of mild steel is affected by $\mathrm{pH}$ (4 to 10) of a solution, temperature and also in the presence of dissolved oxygen. The use of various Organic inhibitors to decrease the rate of corrosion processes has been studied. The industrial importance of corrosion inhibitors is wide spread ranging from pickling to application in water-cooling systems. The selection of an inhibitor for a given system depends on the corrosion medium, the nature of the metal, the magnitude of the charges at the metal solution interface and the catholic reaction. The inhibition of iron corrosion in acidic solutions by organic inhibitor has been well studied ${ }^{1}$ The most efficient inhibitors used in industry are heterocyclic organic compounds having higher electron density on the hetero atoms like "Sulphur", "Oxygen", "Nitrogen" and the molecules with 
multiple bonds through which they are adsorbed on the metal surface, thus help in inhibition of corrosion. Especially inhibitors containing nitrogen atom like long chain nitrogenous organic materials including amines, imines, amides and its derivatives are effective in acid corrosion for industrial applications. Synergistic effects describe the increase in effectiveness of a corrosion inhibitor in the presence of other substances in the corrosive medium ${ }^{2-4}$

\section{Atropine methochloride}

$\mathrm{AMCl}$ is a heterocyclic compound, it contains oxygen and nitrogen. The molecular formula $\left(\mathrm{C}_{18} \mathrm{H}_{26} \mathrm{ClNO}_{3}\right)$ has been tried for its potential in the retardation of corrosion of mild steel. Earlier studies carried out using $\mathrm{AMCl}$ as an inhibitor revealed that it is effective at $10^{-2} \mathrm{M}$ concentrations and the inhibition efficiency was found to be only $40 \%$ with $10^{-4} \mathrm{M}$. To increase the inhibitive effect of $\mathrm{AMCl}$ at the lower concentrations, a set of metal ions and halides are being selected. $\mathrm{AMCl}$ can act as potential inhibitor in synergism with metal ions and halides. In the present investigation, efforts have been taken to study the inhibiting efficiency of $\mathrm{AMCl}$ and the effect of metal ions and halides on mild steel corrosion in $1 \mathrm{M}$ sulphuric acids by weight loss and polarization methods ${ }^{5,6}$

\section{Experimental}

Mild steel was selected as sample material for this study because of it is most versatile, least expensive and wide industrial importance (fabrication of reaction vessels, pipes, tanks, cooling water system $)^{7}$. Sulphuric acid is the choice of test media, due to tremendous increase in industrial activities, like acid cleaning/pickling and descaling. Inhibitors are generally used in industrial processes to control both dissociation and acid consumption. A large sheet of cold rolled mild steel was press cut into rectangular coupons of area $1 \times 5 \mathrm{~cm}^{2}$. They were mechanically polished degreased and washed with distilled water and dried thoroughly for all investigation. The percentage elemental composition was analyzed and found to be as given in the Table 1,

Table 1.The percentage elemental composition

\begin{tabular}{clc}
\hline S. No. & \multicolumn{1}{c}{ Element } & \% Composition of mild steel \\
\hline 1 & Carbon & 0.048 \\
2 & Manganese & 0.335 \\
3 & Silicon & 0.029 \\
4 & Phosphorus & 0.041 \\
5 & Sulphur & 0.025 \\
6 & Chromium & 0.050 \\
7 & Molybdenum & 0.016 \\
8 & Nickel & 0.019 \\
9 & Iron & 99.437 \\
\hline
\end{tabular}

\section{Instrumentation}

The technical methods adapted and the instruments used in the present studies are Denvar balance, Thermostat Solartron (UK) (1284 Z). Techniques; weight loss method and polarisation method ${ }^{8}$

\section{Reagents and solutions}

Sulphuric acid of commercial grade and deionised water are used for the preparation of $1 \mathrm{M}$ acid solutions. 0.1 M solutions of $\mathrm{AMCl}$, nickel sulphate, copper sulphate, potassium iodide, sodium bromide and sodium chloride were prepared. Various concentrations were made from these bulk solutions ${ }^{9}$. 
Triplicate pre-weighed coupons were suspended with the help of glass hook into $100 \mathrm{~mL}$ of acid containing different concentrations of inhibitor for a fixed duration and then removed, washed, dried and reweighed ${ }^{10}$. The average weight losses of the coupons were recorded. The same is done with varying concentrations of $\mathrm{AMCl}$ (from $10^{-2} \mathrm{M}$ to $\left.10^{-6} \mathrm{M}\right)$; At fixed concentration of $\mathrm{AMCl}\left(10^{-4} \mathrm{M}\right)$ and with different concentrations of cations (from $10^{-2} \mathrm{M}$ to $10^{-6} \mathrm{M}$ of $\left.\mathrm{Ni}^{2+} \& \mathrm{Cu}^{2+}\right)$; At fixed concentration of AMCl $\left(10^{-4} \mathrm{M}\right.$ ) and with different concentrations of anions (from $10^{-3} \mathrm{M}^{-6} 10^{-6} \mathrm{M}$ of $\mathrm{I}^{-}, \mathrm{Br}^{-}$and $\mathrm{Cl}^{-}$); $\mathrm{At}$ fixed concentration of $\mathrm{AMCl}\left(10^{-4} \mathrm{M}\right)$ and a fixed concentration of any one of the anions $\left(10^{-3} \mathrm{M}\right.$ of $\mathrm{I}^{-}, \mathrm{Br}^{-}$and $\left.\mathrm{Cl}^{-}\right)$with varying concentrations of cations $\left(10^{-3} \mathrm{M}\right.$ to $10^{-6} \mathrm{M}$ of $\left.\mathrm{Ni}^{2+} \& \mathrm{Cu}^{2+}\right)$. To study the stability of the inhibitor in the presence of various metal ions, $10^{-3} \mathrm{M} \mathrm{I}^{-}$and at various temperatures, temperature study was performed at $298 \mathrm{~K}$, $303 \mathrm{~K}$ and $308 \mathrm{~K}$. The time of immersion of temperature study was fixed as half an hour.

\section{Calculation of corrosion rate}

The corrosion rate for both room temperature and high temperature studies with various concentrations of inhibitor and various concentrations of cations and various concentrations of anions was obtained from the following formula ${ }^{11}$,

$$
\text { Corrosion rate }(\mathrm{mpy})=\frac{436.095 \times 1000 \times \mathrm{W}}{\mathrm{AX} \mathrm{T}}
$$

Where, $\mathrm{W}=$ Weight loss in $\mathrm{g}$

A $=$ Area of specimen in $\mathrm{cm}^{2}$

$\mathrm{T}=$ Exposure time in hours.

The unit of the corrosion rate is in mils penetration per year (mpy).

Percentage inhibition efficiency was calculated from the formula,

$$
\text { Inhibition efficiency }(\%)=\frac{\mathrm{W}_{0}-\mathrm{W}}{\mathrm{W}_{0}} \times 100
$$

Where, $\mathrm{W}_{0}=$ Weight loss of mild steel in the absence of inhibitor

$\mathrm{W}=$ Weight of mild steel in the presence of inhibitor.

Activation energy of corrosion reaction was calculated from Arrhenius equation,

$$
\log \mathrm{K}=\frac{-\mathrm{Ea}+\mathrm{C}}{2.303 \mathrm{RT}}
$$

Where $\mathrm{K}=$ Corrosion rate

$\mathrm{R}=$ gas constant

$\mathrm{T}=$ temperature

$\mathrm{Ea}=$ energy of activation.

\section{Results and Discussion}

The inhibitor effect of $\mathrm{AMCl}$ in $1 \mathrm{M}$ sulphuric acids at various concentrations for 5 hours period of immersion is carried out by weight loss method. As the concentration of the inhibition increased, the inhibitor efficiency also increased. Maximum inhibitor effect was at $10^{-2} \mathrm{M}$ at 5 hours period of immersion was found to be $89.5 \%$ (Table 2).

It may be due to the increase in the surface area of the inhibitor molecules on the metal surface. Inhibitor efficiency of $\mathrm{AMCl}$ was enhanced by the addition of increasing concentrations of metal ions, and the enhancement of inhibition efficiency of $\mathrm{AMCl}$ is observed from $40 \%$ to $50.28 \%$ and $55.25 \%$ in the presence $\mathrm{Ni}^{2+}$ and $\mathrm{Cu}^{2+}$ respectively (Table 3). 
Table 2. Dependence of concentration of $\mathrm{AMCl}$ on the corrosion inhibition of $\mathrm{MS}$ in $1 \mathrm{M}$ $\mathrm{H}_{2} \mathrm{SO}_{4}(5$ hours study).

\begin{tabular}{cccc}
\hline S. No. & Molar Concentration & CR mpy & IE, \% \\
\hline 1 & Blank & 1224.99 & -- \\
2 & $10^{-6}$ & 1190.89 & 3.00 \\
3 & $10^{-5}$ & 935.87 & 24.00 \\
4 & $10^{-4}$ & 731.52 & 41.75 \\
5 & $10^{-3}$ & 333.79 & 75.50 \\
6 & $10^{-2}$ & 142.19 & $89.50^{*}$ \\
\hline
\end{tabular}

Table 3. Effect of metal ions $\left(\mathrm{Ni}^{2+} \& \mathrm{Cu}^{2+}\right)$ on the IE of $\mathrm{AMCl}\left(10^{-3} \mathrm{M}\right)$ in the corrosion of MS in $1 \mathrm{M} \mathrm{H}_{2} \mathrm{SO}_{4}$ (5 h study)

\begin{tabular}{ccccccc}
\hline \multirow{2}{*}{ S. No } & \multicolumn{2}{c}{ Concentration of } & \multicolumn{2}{c}{$\mathrm{Ni}^{2+}$} & \multicolumn{2}{c}{$\mathrm{Cu}^{2+}$} \\
\cline { 2 - 7 } & AMCl, M & Metal ions M & CR, mpy & IE, \% & CR, mpy & IE, \% \\
\hline 1 & Blank & Blank & 1578.98 & -- & 1449.87 & -- \\
2 & $10^{-4}$ & $10^{-6}$ & 949.85 & 40.89 & 754.52 & 48.56 \\
3 & $10^{-4}$ & $10^{-5}$ & 867.70 & 48.36 & 755.30 & 50.10 \\
4 & $10^{-4}$ & $10^{-4}$ & 831.77 & 49.14 & 733.65 & 51.42 \\
5 & $10^{-4}$ & $10^{-3}$ & 816.06 & 50.28 & 693.52 & $52.06^{*}$ \\
\hline
\end{tabular}

CR-corrosion rate; AMCl:Atropiune methochloride; IE: Inhibition efficiency; mpy: mils penetration per year MS -Mild steel

This might be due to the synergistic influence of metal cations on $\mathrm{AMCl}$. It may therefore be assumed that the rate of corrosion goes on decreasing with increasing concentration of the metal. Increase in concentration of halide ions with $10^{-4} \mathrm{M} \mathrm{AMCl}$ increased the inhibition efficiency from 37.43 to $75.06 \%, 36.20-52.65 \%$ and 38.64 to $50.43 \%$ for iodide, bromide and chloride ions respectively (Table 4)

Table 4. Effect of various halides on the corrosion inhibition of MS in the presence of $\mathrm{AMCl}\left(10^{-4} \mathrm{M}\right)$ in $1 \mathrm{M} \mathrm{H}_{2} \mathrm{SO}_{4}(5 \mathrm{~h}$ study)

\begin{tabular}{ccccccccc}
\hline \multirow{2}{*}{ S.No } & \multicolumn{2}{c}{ Concentartion of } & \multicolumn{2}{c}{$\mathrm{I}^{-}$} & \multicolumn{2}{c}{$\mathrm{Br}^{-}$} & \multicolumn{2}{c}{$\mathrm{Cl}^{-}$} \\
\cline { 3 - 9 } & AMCl, M Halides, M & CR, mpy & IE,\% & CR, mpy & IE, \% & CR, mpy & IE, \% \\
\hline 1 & Blank & Blank & 1577.73 & -- & 1577.73 & -- & 1577.73 & -- \\
2 & $10^{-4}$ & $10^{-6}$ & 1003.56 & 37.43 & 1022.93 & 36.20 & 984.41 & 38.64 \\
3 & $10^{-4}$ & $10^{-5}$ & 930.62 & 42.05 & 833.96 & 48.18 & 908.82 & 43.43 \\
4 & $10^{-4}$ & $10^{-4}$ & 769.99 & 52.24 & 808.68 & 49.79 & 825.96 & 48.69 \\
5 & $10^{-4}$ & $10^{-3}$ & 410.22 & $75.06^{*}$ & 763.45 & 52.65 & 798.58 & 50.43 \\
\hline
\end{tabular}

Iodide was found to be more effective than chloride and bromide. The enhanced inhibition efficiency is due to joint adsorption of halide ions and inhibitor cations or molecules ${ }^{12}$. The high efficiency of iodide can be explained as due to its larger ionic size, stronger adsorption due to easy polarizability of its electron shells and possible formation of surface layer on the metal with the inhibitor. Analysis of Table 5, $6 \& 7$ reveals that there is enhancement in the inhibition efficiency from $40 \%\left(10^{-4} \mathrm{M} \mathrm{AMCl}\right)$ to $98.90 \%$ and $99.54 \%$ 
due to the presence of $10^{-3} \mathrm{M} \mathrm{Ni}^{2+}$ and $10^{-3} \mathrm{M} \mathrm{Cu}^{2+}$ in the presence of and $10^{-3} \mathrm{M} \mathrm{I}^{-}$. The enhancement in the inhibition efficiency from $40 \%\left(10^{-4} \mathrm{M} \mathrm{AMCl}\right)$ to $69.08 \%$ and $68.13 \%$ by the addition of $10^{-3} \mathrm{M} \mathrm{Ni}^{2+}$ and $10^{-3} \mathrm{M} \mathrm{Cu}^{2+}$ in the presence of $10^{-3} \mathrm{M} \mathrm{Br}^{-}$. The inhibition efficiency increase from $40 \%\left(10^{-4} \mathrm{M} \mathrm{AMCl}\right)$ to $64.99 \%$ and $59.87 \%$ in the case addition of $10^{-3} \mathrm{M} \mathrm{Ni}^{2+}$ and $10^{-3} \mathrm{M} \mathrm{Cu}^{2+}$ in $10^{-3} \mathrm{M} \mathrm{Cl}^{-}$respectively. This is due synergistic effect of metal ions and halides ${ }^{13,14}$.

Table 5. Role of metal ions $\left(\mathrm{Ni}^{2+} \& \mathrm{Cu}^{2+}\right)$ and iodide $\left(10^{-3} \mathrm{M}\right)$ on the corrosion inhibition of $\mathrm{MS}$ in the presence of $10^{-4} \mathrm{M} \mathrm{AMCl}$ in $1 \mathrm{M} \mathrm{H}_{2} \mathrm{SO}_{4}$

\begin{tabular}{ccccccccc}
\hline \multirow{2}{*}{ S. No. } & \multicolumn{3}{c}{ Concentration } & of & \multicolumn{2}{c}{$\mathrm{Ni}^{+2}$} & \multicolumn{2}{c}{$\mathrm{Cu}^{+2}$} \\
\cline { 2 - 8 } & AMCl, M & I- M & Metal ions, M & CR, mpy & IE, \% & CR, mpy & IE, \% \\
\hline 1 & Blank & Blank & Blank & 1135.59 & - & 1135.59 & - \\
2 & $10^{-4}$ & $10^{-3}$ & $10^{-6}$ & 27.91 & 98.64 & 28.12 & 98.62 \\
3 & $10^{-4}$ & $10^{-3}$ & $10^{-5}$ & 24.100 & 98.90 & 31.54 & 98.32 \\
4 & $10^{-4}$ & $10^{-3}$ & $10^{-4}$ & 33.72 & 98.13 & 26.20 & 98.79 \\
5 & $10^{-4}$ & $10^{-3}$ & $10^{-3}$ & 40.99 & 97.49 & 18.94 & $99.54 *$ \\
\hline
\end{tabular}

Table 6. Tabulation of $\mathrm{Cr}$ and $\mathrm{IE}$ for the various concentrations of different metal ions $\left(\mathrm{Ni}^{2+}\right.$ $\& \mathrm{Cu}^{2+}$ ) with $10^{-4} \mathrm{M} \mathrm{AMCl}$ and $10^{-3} \mathrm{M}$ bromide in $1 \mathrm{M} \mathrm{H}_{2} \mathrm{SO}_{4}(5 \mathrm{~h}$ study)

\begin{tabular}{cccccccc}
\hline \multirow{2}{*}{ S. No } & \multicolumn{3}{c}{ Concentration of } & \multicolumn{2}{c}{$\mathrm{Ni}^{2+}$} & \multicolumn{2}{c}{$\mathrm{Cu}^{2+}$} \\
\cline { 2 - 8 } & AMCl, M & Br-M & Metal ions, M & CR, mpy & IE, \% & CR, mpy & IE, \% \\
\hline 1 & Blank & Blank & Blank & 913.90 & - & 913.90 & - \\
2 & $10^{-4}$ & $10^{-3}$ & $10^{-6}$ & 370.96 & 60.48 & 471.27 & 60.40 \\
3 & $10^{-4}$ & $10^{-3}$ & $10^{-5}$ & 295.13 & 68.79 & 366.61 & 60.96 \\
4 & $10^{-4}$ & $10^{-3}$ & $10^{-4}$ & 295.13 & 68.79 & 366.61 & 60.96 \\
5 & $10^{-4}$ & $10^{-3}$ & $10^{-3}$ & 292.47 & 69.08 & 301.19 & 68.13 \\
\hline
\end{tabular}

Table 7. Variation of IE in the presence of various concentrations of different metal ions $\left(\mathrm{Ni}^{2+} \& \mathrm{Cu}^{2+}\right)$ with $10^{-4} \mathrm{M} \mathrm{AMCl}$ and $10^{-3} \mathrm{M}$ chloride in $1 \mathrm{M} \mathrm{H}_{2} \mathrm{SO}_{4}(5 \mathrm{~h}$ study $)$

\begin{tabular}{cccccccc}
\hline \multirow{2}{*}{ S. No } & \multicolumn{3}{c}{ Concentration } & of & \multicolumn{2}{c}{$\mathrm{Ni}^{2+}$} & \multicolumn{2}{c}{$\mathrm{Cu}^{2+}$} \\
\cline { 2 - 7 } & AMCl, M & Cl- M & Metal ions, M & CR, mpy & IE, \% & CR, mpy & IE, \% \\
\hline 1 & Blank & Blank & Blank & 892.10 & - & 892.10 & - \\
2 & $10^{-4}$ & $10^{-3}$ & $10^{-6}$ & 514.15 & 51.36 & 542.50 & 48.62 \\
3 & $10^{-4}$ & $10^{-3}$ & $10^{-5}$ & 435.65 & 58.96 & 517.78 & 51.01 \\
4 & $10^{-4}$ & $10^{-3}$ & $10^{-4}$ & 410.58 & 61.387 & 448.25 & 57.74 \\
5 & $10^{-4}$ & $10^{-3}$ & $10^{-3}$ & 373.14 & 64.99 & 426.20 & 59.87 \\
\hline
\end{tabular}

To study the stability of the inhibitor in the presence of various cations and $10^{-3} \mathrm{M} \mathrm{I}^{-}$ Temperature study has been performed at $298 \mathrm{~K}, 303 \mathrm{~K}$ and $308 \mathrm{~K}$. The time of immersion of temperature study was fixed as half an hour. Results are tabulated in Table 8. On increasing the concentration of $\mathrm{Ni}^{2+}$, the enhancement of inhibition efficiency of $10^{-4} \mathrm{M}$ 
$\mathrm{AMCl}$ with $10^{-3} \mathrm{M} \mathrm{I}$ in $1 \mathrm{M} \mathrm{H}_{2} \mathrm{SO}_{4}$ also increased from $91 \%$ to $94 \%$. As the temperature increased from $298 \mathrm{~K}$ to $308 \mathrm{~K}$, the inhibition efficiency gradually decreased. At $298 \mathrm{~K}$, the efficiency was found to be $94 \%, 86 \%$ at $303 \mathrm{~K}$ and $79.10 \%$ at $308 \mathrm{~K}$ and the inhibitor was effective up to $303 \mathrm{~K}$. The standard electrode potential $\mathrm{Ni}^{2+} / \mathrm{Ni}(-0.250 \mathrm{~V})$ and of $\mathrm{Fe}^{2+} / \mathrm{Fe}$ $(-0.4402 \mathrm{~V})$. The differentiation is small, so metal Nickel hardly form a protection film on the steel surface. Therefore, the effect of $\mathrm{Ni}^{2+}$ for steel was not obvious.

Table 8. Variation of IE with different concentration of $\mathrm{Ni}^{2+}$ in the presence of $10^{-4} \mathrm{M}$ $\mathrm{AMCl}$ and $10^{-3} \mathrm{M}$ iodide in $1 \mathrm{M} \mathrm{H}_{2} \mathrm{SO}_{4}$ at different temperatures (1 $\mathrm{h}$ study)

\begin{tabular}{cccccccccc}
\hline \multirow{2}{*}{ S. No } & \multicolumn{2}{c}{ Concentration of } & \multicolumn{2}{c}{$298 \mathrm{~K}$} & \multicolumn{2}{c}{$303 \mathrm{~K}$} & \multicolumn{2}{c}{$308 \mathrm{~K}$} \\
\cline { 2 - 9 } & AMCl, M & $\mathrm{I}^{-}, \mathrm{M}$ & $\mathrm{Ni}^{+2}$ & CR. mpy & IE, \% & CR, mpy & IE, \% & CR, mpy & IE, \% \\
\hline 1 & Blank & Blank & Blank & 3886.62 & - & 9749.92 & - & 21869.72 & - \\
2 & $10^{-4}$ & $10^{-3}$ & $10^{-6}$ & 371.69 & 91.36 & 3463.67 & 65.38 & 5648.33 & 56.32 \\
3 & $10^{-4}$ & $10^{-3}$ & $10^{-5}$ & 306.32 & 93.66 & 2996.44 & 70.33 & 4988.23 & 61.84 \\
4 & $10^{-4}$ & $10^{-3}$ & $10^{-4}$ & 275.34 & 93.83 & 2704.33 & 73.18 & 4767.52 & 63.22 \\
5 & $10^{-4}$ & $10^{-3}$ & $10^{-3}$ & 271.18 & 94.08 & 1407.23 & 86.33 & 2799.89 & 79.10 \\
\hline
\end{tabular}

From the Table 9, it is observed that there is increase in enhancement of inhibition efficiency of $10^{-4} \mathrm{M}$ AMCl with $10^{-3} \mathrm{M} \mathrm{I}^{-}$in $1 \mathrm{M} \mathrm{H}_{2} \mathrm{SO}_{4}$ as the concentration of $\mathrm{Cu}^{2+}$ increased. The inhibition efficiency increased from $89.89 \%$ to $95.84 \%$. There is a decrease in inhibition efficiency the temperature from $298 \mathrm{~K}$ to $308 \mathrm{~K}$. The inhibition efficiency was found to be $95.84 \%$ at $298 \mathrm{~K}, 94.68 \%$ at $303 \mathrm{~K}$ and $78.05 \%$ at $308 \mathrm{~K}$. Adsorption of $\mathrm{Cu}^{2+}$ on the steel at lower concentration may have been an important reason for the inhibition also the oxidizing reaction ${ }^{15}$

$$
\mathrm{Cu}^{2+}+\mathrm{Fe} \longrightarrow \mathrm{Cu}+\mathrm{Fe}^{2+}
$$

Table 9. Variation of IE with different concentrations of $\mathrm{Cu}^{2+}$ in the presence of $10^{-4} \mathrm{M}$ $\mathrm{AMCl}$ and $10^{-3} \mathrm{M}$ iodide in $1 \mathrm{M} \mathrm{H}_{2} \mathrm{SO}_{4}$ at different temperatures ( $1 \mathrm{~h}$ study)

\begin{tabular}{|c|c|c|c|c|c|c|c|c|c|}
\hline \multirow{2}{*}{ S.No } & \multicolumn{2}{|c|}{ Concentration of } & \multicolumn{3}{|c|}{$298 \mathrm{~K}$} & \multicolumn{2}{|l|}{$303 K$} & \multicolumn{2}{|l|}{$308 \mathrm{~K}$} \\
\hline & $\mathrm{AMCl}, \mathrm{M}$ & $\mathrm{I}^{-}, \mathrm{M}$ & $\mathrm{Cu}^{2+}$ & $\mathrm{CR}, \mathrm{mpy}$ & $\mathrm{IE}, \%$ & $\mathrm{CR}, \mathrm{mpy}$ & IE, \% & $\mathrm{CR}, \mathrm{mpy}$ & IE, \% \\
\hline 1 & Blank & Blank & Blank & 3886.71 & ---- & 9749.71 & ----- & 12774.13 & ---- \\
\hline 2 & $10^{-4}$ & $10^{-3}$ & $10^{-6}$ & 431.74 & 89.89 & 2337.47 & 76.02 & 5922.17 & 53.64 \\
\hline 3 & $10^{-4}$ & $10^{-3}$ & $10^{-5}$ & 200.60 & 95.84 & 518.95 & 94.68 & 2804.09 & 78.05 \\
\hline 4 & $10^{-4}$ & $10^{-3}$ & $10^{-4}$ & 126.47 & 97.75 & 466.62 & 95.21 & 1077.16 & 91.57 \\
\hline 5 & $10^{-4}$ & $10^{-3}$ & $10^{-3}$ & 100.30 & 98.42 & 283.47 & 97.09 & 889.63 & 93.04 \\
\hline
\end{tabular}

The kinetic parameter of the systems under consideration was evaluated using the data obtained from weight loss method for various concentrations of different metal ions, $10^{-4} \mathrm{M}$ $\mathrm{AMCl}$ and $10^{-3} \mathrm{M} \mathrm{I}^{-}$at higher temperatures. The activation energy values presented in the Table 10 and 11 were found to be greater in the presence of synergistic metal ions and halides and it may be interpreted ${ }^{16}$. This indicated the physical adsorption of inhibitor molecule on the metal surface. Higher activation energy for the corrosion process in the presence of synergistic ions lead to the conclusion that the inhibitor might have been bounded to the surface by specific adsorption process and as a result of which a surface filling of reaction product may be formed on the metal surface resulting in the inhibition. With the help of the temperature studies results, thermodynamic parameters such as $\Delta \mathrm{G}, \Delta \mathrm{H}$ and $\Delta \mathrm{S}$ were 
calculated. The values of thermodynamic parameters are represented in the Tables 10 and 11 for various concentrations of cations in the presence of $10^{-3} \mathrm{M} \mathrm{I}$ and $10^{-4} \mathrm{M} \mathrm{AMCl}$. The negative values of $\Delta \mathrm{G}$ and $\Delta \mathrm{S}$ values are characteristic of strong interaction between the inhibitor and the metal surface ${ }^{17}$. The free energy values for the investigated inhibitor decreases with increases in concentration of the investigated metal ions and with increase in temperature.

Table 10. Kinetic parameters of corrosion and thermodynamic parameters of adsorption of $\mathrm{AMCl}, \mathrm{I}^{-}$and $\mathrm{Ni}^{2+}$ ions for $\mathrm{MS}$ in $\mathrm{H}_{2} \mathrm{SO}_{4}$

\begin{tabular}{|c|c|c|c|c|c|c|}
\hline \multirow[t]{2}{*}{$\begin{array}{l}\text { Concentration } \\
\mathrm{Ni}^{2+}, \mathrm{M}\end{array}$} & \multirow{2}{*}{$\begin{array}{c}\text { Activation } \\
\text { energy, } \\
\text { J/mol }\end{array}$} & \multicolumn{3}{|c|}{$\begin{array}{l}\text { Free energy of adsorption } \\
\qquad(-\Delta \mathrm{G}), \mathrm{KJ} / \mathrm{mol}\end{array}$} & \multirow{2}{*}{$\begin{array}{c}\text { Entropy } \\
\text { change } \\
\Delta \mathrm{S}, \mathrm{KJ} / \mathrm{mol}\end{array}$} & \multirow[t]{2}{*}{$\begin{array}{c}\text { Heat of adsorption } \\
\Delta \mathrm{H}, \mathrm{KJ} / \mathrm{mol}\end{array}$} \\
\hline & & $298 \mathrm{~K}$ & $303 \mathrm{~K}$ & $308 \mathrm{~K}$ & & \\
\hline Bla & -45379.727 & -- & 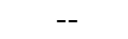 & -- & . & -- \\
\hline 10 & .091 & 54.0763 & 1.2368 & 6 & 0.09 & 4 \\
\hline $10^{-5}$ & -97172.746 & 48.5484 & 45.5469 & 45.8678 & -0.10 & \\
\hline $10^{-4}$ & -99087.460 & 42.7621 & 39.6622 & 40.4578 & -0.124192 & 82.54679 \\
\hline $10^{-3}$ & -91734.967 & 36.7178 & 35.6240 & 36.7782 & -0.126415 & 78.31579 \\
\hline
\end{tabular}

Table 11. Kinetic parameters of corrosion and thermodynamic parameters of adsorption of $\mathrm{AMCl}, \mathrm{I}^{-}$and $\mathrm{Cu}^{2+}$ ions for $\mathrm{MS}$ in $1 \mathrm{M} \mathrm{H}_{2} \mathrm{SO}_{4}$

\begin{tabular}{|c|c|c|c|c|c|c|}
\hline \multirow[t]{2}{*}{$\begin{array}{c}\text { Concentration } \\
\mathrm{Cu}^{2+}, \mathrm{M}\end{array}$} & \multirow[t]{2}{*}{$\begin{array}{c}\text { Activation } \\
\text { energy, } \mathrm{J} / \mathrm{mol}\end{array}$} & \multicolumn{3}{|c|}{$\begin{array}{l}\text { Free energy of adsorption } \\
\qquad(-\Delta \mathrm{G}), \mathrm{KJ} / \mathrm{mol}\end{array}$} & \multirow{2}{*}{$\begin{array}{c}\text { Entropy } \\
\text { change } \\
\Delta \mathrm{S}, \mathrm{KJ} / \mathrm{mol}\end{array}$} & \multirow{2}{*}{$\begin{array}{c}\text { Heat of } \\
\text { adsorption } \Delta H \text {, } \\
\mathrm{KJ} / \mathrm{mol}\end{array}$} \\
\hline & & $298 K$ & $303 \mathrm{~K}$ & $308 \mathrm{~K}$ & & \\
\hline Blank & -45341.432 & -- & -- & -- & -- & -- \\
\hline $10^{-6}$ & -95526.091 & 53.6260 & 52.5003 & 51.5001 & -0.104208 & 86.81445 \\
\hline $10^{-5}$ & -115879.503 & 49.7346 & 51.1256 & 48.1786 & -0.160002 & 101.9087 \\
\hline $10^{-4}$ & -117162.362 & 44.9876 & 45.2008 & 44.5612 & -0.166654 & 99.11122 \\
\hline $10^{-}$ & -.108278 .088 & 39.2345 & 40.3333 & 38.9632 & -0.120253 & 78.71132 \\
\hline
\end{tabular}

\section{Conclusions}

The investigations of the study of "Synergistic effect of metal ions and halides on corrosion inhibition of mild steel in the presence of atropine methochloride in acidic medium" reveal that;

- As the concentration of $\mathrm{AMCl}$ increased, the inhibition efficiency also increased.

- Halide ions decreased the corrosion rate of mild steel in sulphuric acid. A steady decrease in corrosion rate is observed by increasing the concentration of iodide, chloride and bromide ions. The decrease is maximum with iodide ions. Enhancement of inhibition efficiency of $10^{-4} \mathrm{M} \mathrm{AMCl}$ in the presence of different cations with $10^{-3} \mathrm{M}$ iodide ion and at higher temperature was found to be maximum.

- Activation energy in the presence of synergistic metal ions and halides was found to be higher than the blank values. This indicated that the physical adsorption of inhibitor molecule on the metal surface.

- $\quad$ The negative values of the free energy of adsorption indicate that there was a strong interaction between the inhibitor molecules and metal surface values of $\Delta H$ and $\Delta S$ were found to be inter related with $\Delta \mathrm{G}$. The values of $\Delta \mathrm{G}$ could confirm the adsorption process is physical adsorption. 


\section{References}

1. Abdel Hamid.Z. Anti- Corros Meth Mater., 1997, 44,389.

2. Ajmal M, Rawath J and Quraishi MA, Anti- Corros Meth Mater., 1998, 45, 419.

3. Quarishi M A, Rawat J and Ajmal M, Corrosion and its control, proceedings, Int. Conf. Corrosion , 1997, 2, 634

4. Abdel.A.M.S and Saied, Trans Soc Adv Electrochem Sci Technol., 1981, 16,197.

5. Ajmal M, Jamal D and Quaraishi.M, Bull Electrochem, 1998, 14,29 - 30.

6. Azim.S S and Muralidharan S, J Appl Electrochem., 1995, 25, 495-500.

7. Upadhyay R K and Mathur S P, E- J Chem., 2007, 4, 408-414.

8. Rajendaran S, Apparo B V and Palaniswamy N, Anti-Corros Meth. Mater., 2000, 47, 294.

9. Chakraborthy S B and Chaudri, J Indian Chem Soc.,1996,73,113-118.

10. Fontana G, Norbert and Greeno D, Corros Engineering, 1971, 27, 194-217

11. Gomma G K, Mater Chem Phys., 1998, 55,131-138.

12. Gomma G.K, Bull Electrochem., 1999, 15, 1-7.

13. Gonazalez Y, Lafont M C, Pebere N and Moran F, J Appl Electrochem., 1996, 26, 1259-1265.

14. Syed Azim S and Venkatakrishna Iyer S, Eighth national congress on corrosion control, Kochi, 1998, 115.

15. Tourillen G and Garnier F, J Electroanal Chem., 1982, 135, 173-178.

16. Waltman R J, Diaz A F and Bargon J, J Phys Chem., 1984, 88, 4343-4346.

17. Yadav P N S and Singh A K, Asian J Chem., 1999, 22, 580-83. 


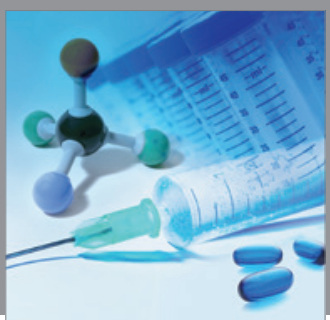

International Journal of

Medicinal Chemistry

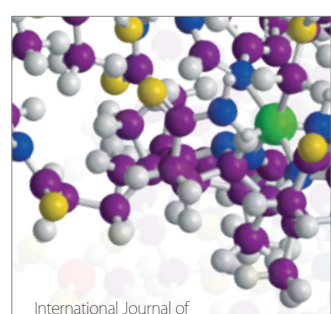

Carbohydrate Chemistry

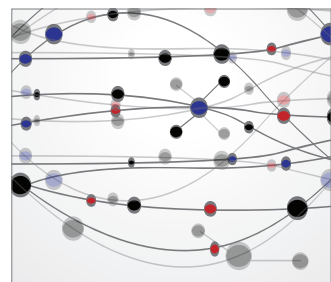

The Scientific World Journal
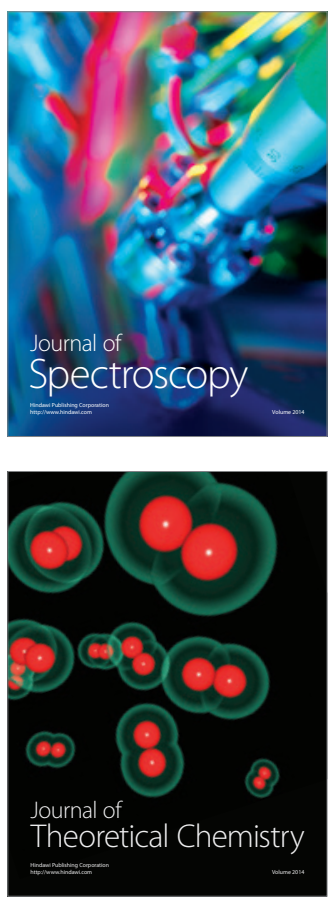
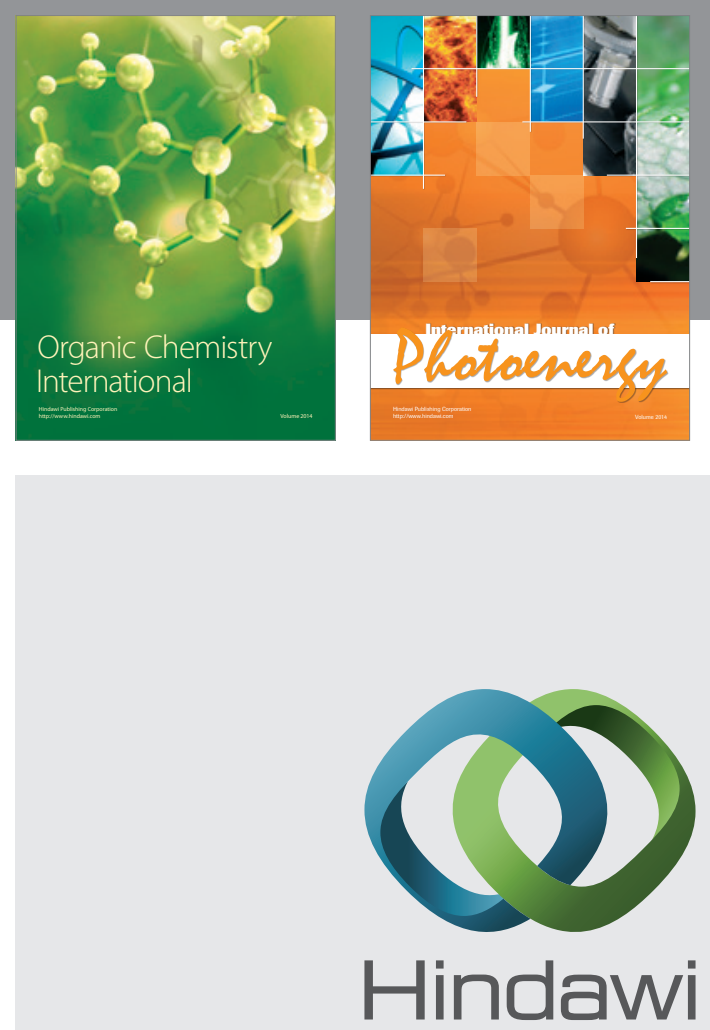

Submit your manuscripts at

http://www.hindawi.com
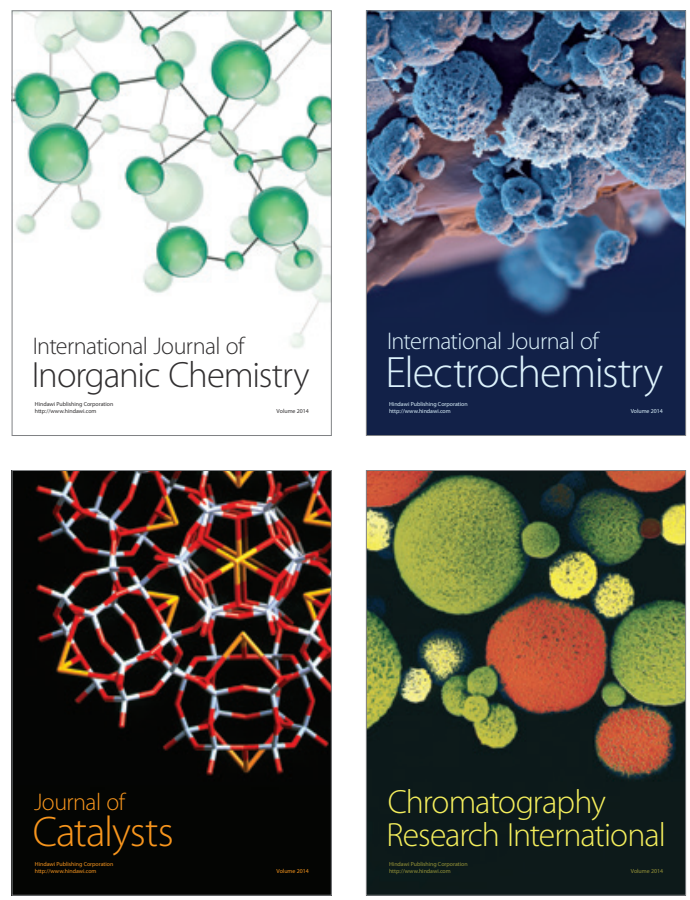
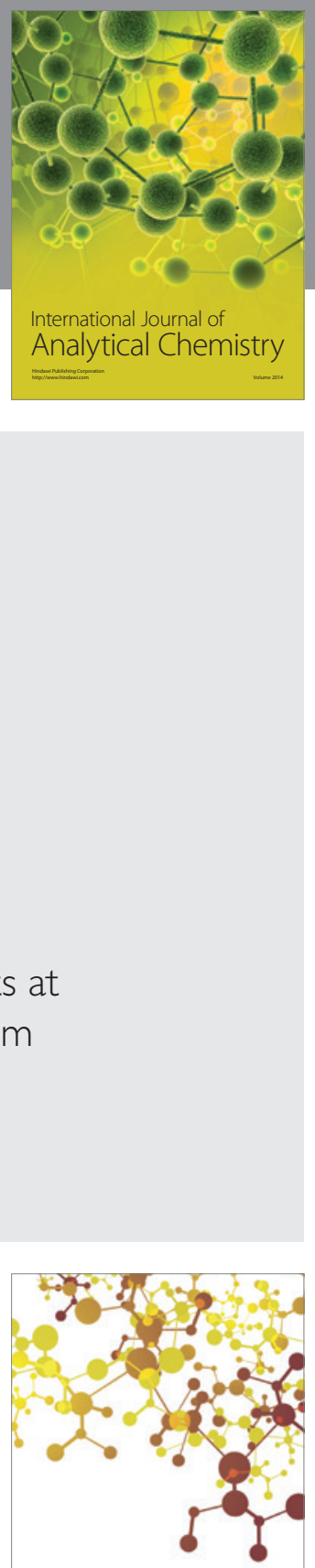

Journal of

Applied Chemistry
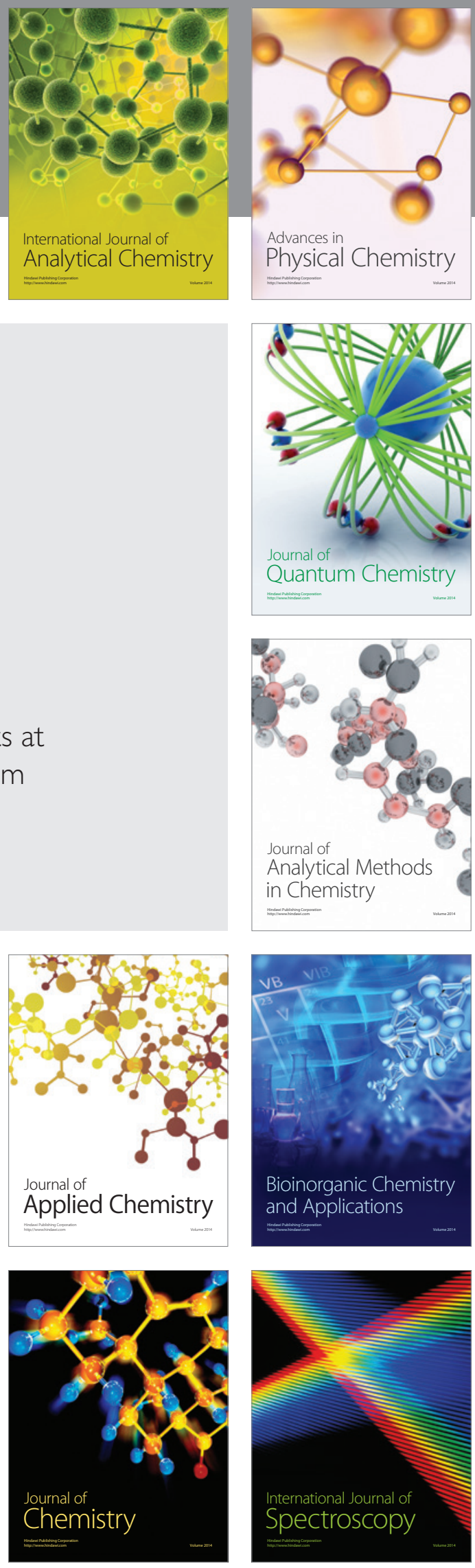